\title{
PENGARUH WAKTU PENCETAKAN KOMPON \\ POLIPROPILENE UNTUK ACUAN SEPATU
}

\author{
Oleh : Sunarso, Hs., Hernadi Surip
}

\begin{abstract}
Polypropylene is the most important polymer in poliolafine. In this study polypropylene is added with kaolin, in the batch, the varied time used for moulding was $13,15,17,19$, and 21 minutes, while the temperature and pressure was $190 \mathrm{C}, 150 \mathrm{~kg} / \mathrm{cm} 2$.

The porpuse of the varied time used is to detect how for the influence of time to words of hardness and impact resistance of polypropylene prepared for shoe last.

It can be found from the resuit that time does not have influence on the impact resistance of polypropylene compound used for shoe last, but the longer the time used the hardness will be decreased.

The highest test result of hardness and impact resistance was achieved by polypropylene compound which was moulded in 13 minutes $(75,53$ shore D, $2,5831 \mathrm{~kg} \mathrm{~cm} / \mathrm{cm})$.
\end{abstract}




\section{INTISARI}

Polipropilene merupakan jenis polimer yang penting diantara poliolefin. Pada penelitian ini polipropilene ditambah filler kao!in, dengan waktu pencetakan bervariasi, 13, 15, 17, 19, dan 21 menit pada suhu dan tekanan tetap $(190 \mathrm{C}, 150 \mathrm{~kg} / \mathrm{cm} 2)$.

Waktu yang bervariasi dimaksudkan untuk mengetahui sejauh mana pengaruh waktu proses terhadap kekerasan dan ketahanan pukul takik pada kompon polipropilene untuk acuan sepatu.

Ternyata waktu proses pencetakan kompon polipropilene untuk acuan sepatu tidak berpengaruh pada ketahanan pukul takik, tetapi berpengaruh pada kekerasan dimana semakin lama waktu proses semakin turun kekerasannya. Hasil uji kekerasan dan ketahanan pukul takik yang tertinggi dicapai oleh kompon yang diproses dengan waktu 13 menit $(75,53$ shore $\mathrm{D}$, $2,5831 \mathrm{~kg} \mathrm{~cm} / \mathrm{cm})$.

\section{PENDAHULUAN}

Sebagian besar produk barang-barang plastik di Indonesia menggunakan bahan baku resin PVC, tetapi sejak tahun 1954 banyak usaha untuk memproduksi plakstik dari jenis poliolefin diantaranya polipropilene.

Pembuatan kompon polipropilene berbeda dengan cara pembuatan kompon PVC karena polipropilene berbentuk pellet sedangkan PVC berbentuk powder. Kaolin merupakan salah satu jenis filler yang dipakai pada proses pembuatan barang-barang plastik yang cukup baik. Maka perlu diadakan penelitian pembuatan kompon polipropilene ditambah dengan filler kaolin.

Pada penelitian ini waktu proses bervariasi dari 13, 15, 17, 19, dan 21 menit, dengan suhu tetap $190 \mathrm{C}$ dan tekanan tetap $150 \mathrm{~kg} / \mathrm{cm} 2$. Waktu proses pencetakan bervariasi dimaksudkan untuk mengetahui sejauh mana pengaruh waktu proses ternadap mutu kompon yang dihasilkan, dimana suku proses dengan jahan polipropilene adalah $180 \mathrm{C}-280 \mathrm{C}$.

Dalam proses pembuatan barang-barang plastik diantaranya adalah proses injection moulding dan proses compresion moulding. Proses injection moulding merupakan proses siklis, prinsip kerjanya adalah penginjeksian bahan plastik lumer kedalam cetakan dan cetakan tersebut langsung didinginkan. Proses compression moulding prinsip kerjanya adalah material dituangkan kedalam cetakan, dan produk yang dihasilkan sesuai dengan bentuk cetakan.

Sedangkan penelitian ini bertujuan untuk mendapatkan kompon polipropilene yang sesuai dengan persyaratan untuk acuan sepatu. 
urut seorang berkebangsaan Itali bernama C. Natta, pada tahun 1954 emukan jenis polipropilene, dimana polipropilene tersebut merupakan her yang penting diantara poliolefin.

upun polipropilene dan poliethilene mempunyai kesamaan, tetapi ada perbedaannya.

daan-perbedaan tersebut antara lain :

olipropilene mempunyai density 0,90 , sedangkan poliethilene densityya $0,941-0,965$.

olipropilene sedikit kaku tetapi lebih keras, dengan titik rapuh lebih nggi.

olipropilene mudah retak.

Jika dibandingkan dengan High Density Polyethylene, polipropilene punyai sifat yang lebih baik pada kekuatan tarik, hardness, stiffnes kehan, begitu pula terhadap air, solvent, minyak, oli, dan bahan-bahan

a.

kasi barang plastik yang terbuat dari polipropilene meliputi bidang rutangga, pengemas, kedokteran, teknik, laminasi, kendaraan bermotor ropilene juga dapat diproses menjadi pipa.

us molekul polipropilene dapat dilihat sebagai berikut :

$$
\text { Polipropilene - }\left(\mathrm{CH}_{2}-\mathrm{C}-\right)
$$

pembuatan barang-barang plastik biasanya juga ditambahkan bahan isi (filler), sedangkan jenis filler cukup banyak jenis dan macamnya, a satunya adalah kaolin.

lin digunakan secara luas dalam pembuatan plastik, karena sifat-sifat in menunjang terbentuknya sifat-sifat plastik, seperti kehalusan permu, penampilan yang lebih menarik, stabilitas bentuk dan ketahanan terpat-zat kimia. Pada pembuatan PVC, kaolin digunakan sebagai guat sehingga plastik lebih tahan lama.

am pembuatan produk-produk barang plastik ada beberapa cara proses taranya injection moulding, extrusion, blow moulding, thermoforming calendering.

ses injection moulding merupakan proses penyemprotan/penginjeksian tik lumer melalui lubang yang sempit kedalam suatu ruangan yang diMengalimya plastik lumer didalam cetakan pada umumnya melalui e, runner, gate kemudian baru masuk kedalam ruangan yang merupaproduk sendiri.
Pengisian plastik lumer kedalam cetakan melalui lubang kecil memerlukan tekanan (injection pressure) yang tinggi. Selain itu diperlukan gaya yang benar pada cetakan (clamping force) agar pada saat proses injeksi, cetakan tetap dalam keadaan tertutup rapat. Oleh karena itu mesin injection moulding pada umumnya menggunakan sistem hydraulic.

\section{MATERI DAN METODE}

\section{A. Materi penelitian}

\section{Bahan dan peralatan}

\subsection{Bahan}

Bahan yang digunakan dalam penelitian ini adalah :

Polipropilene, dan filler kaolin.

\subsection{Peralatan}

Alat yang digunakan adalah timbangan analitis, banbury mixer hydraulic press, stop wacth, aluminium foil, hardness tester dan alat uji ised impact tester.

\section{B. Metode penelitian}

\section{Proses}

Pada pembuatan kompon polipropilene yang uitambah dengan filler kaolin dapat diuraikan sebagai berikut :

Bahan polipropilene ditambah filler kaolin dengan perbandingan berat adalah 100 bagian polipropilene dengan 30 bagian kaolin, ditimbang dan selanjutnya dimasukkan kedalam banbury mixer, agar polipropilene dengan kaolin dapat tercampur sempurna maka dalam proses ini dipanaskan pada suhu $225^{\circ} \mathrm{C}-250^{\circ} \mathrm{C}$ selama $+2-3$ menit. Polipropilene yang ditambah dengan kaolin merupakan kompon, dan untuk contoh uji kompon tersebut dibuat slab dengan ukuran $(20 \times 20)$ dengan tebal $3 \mathrm{~cm}$.

\section{2. Pengujian}

\subsection{Pengujian kekerasan (Shore D)}

Untuk mengetahui kekerasan slab kompon polipropilene digunakan alat hardness tester (Shore D). Contoh uji diletakkan dibawah jarum, kemudian alat tersebut ditekan sampai jarum menunjuk pada angka maksimum, dimana angka tersebut merupakan angka penunjuk nilai kekerasan kompon polipropilene.

\subsection{Pengujian ketahanan pukul takik (sesuai SII 0673 - 82)}

Angka ketahanan pukul takik adalah menentukan besarnya keta- 
hanan pukul untuk memukul suatu contoh uji sampai putus. Contoh uji dikondisioning pada suhu $23^{\circ} \mathrm{C} \pm 2^{\circ} \mathrm{C}$ dengan kelembaban sekurang-kurangnya $50 \pm 5 \%$ selama $40 \mathrm{jam}$.

Cara kerja, contoh uji dipasang pada penjepit dengan takik menghadap kearah pemukul dan puncak takik satu garis dengan permukaan penjepit.

Pemukul yang digunakan mempunyai berat tertentu dan ujung lengan dapat bergerak bebas, contoh uji dipukul sampai putus.

$$
\begin{aligned}
\text { Ketahanan pukul takik } & =\frac{\text { Energi }(\mathrm{kg} \mathrm{cm})}{\text { Tebal benda uji }(\mathrm{cm})} \\
\text { Dimana : Energi } & =\text { W.R }(\operatorname{Cos} \beta-\operatorname{Cos} \alpha) \\
\text { W } & =1,38 \mathrm{~kg} \\
\mathrm{R} & =1,27 \mathrm{~cm} \\
\alpha & =135
\end{aligned}
$$

Besarnya energi yang diperlukan untuk memukul benda uji dapat dibaca dalam tabel energi.

\section{HASIL PENELITIAN DAN PEMBAHASAN}

\section{Hasil penelitian}

1.1. Hasil penelitian untuk kekerasan kompon polipropilene datanya dapat dilihat dalam tabel 1 .

Tabel 1 : Data hasil uji kekerasan (Shore D)

\begin{tabular}{c|c|c|c|c}
\hline \multirow{2}{*}{ Waktu } & \multicolumn{3}{|c|}{ Ulangan } & \multirow{2}{*}{ Rata-rata } \\
\cline { 2 - 4 } & 1 & 2 & 3 & \\
\hline \multirow{2}{*}{13} & 75 & 75 & 76 & 75,53 \\
15 & 75 & 75 & 73 & 74,33 \\
17 & 72 & 75 & 76 & 73,33 \\
19 & 70 & 71 & 71 & 70,66 \\
21 & 70 & 70 & 70 & 70,00 \\
\hline
\end{tabular}

1.2. Hasil penelitian untuk ketahanan pukul takik $(\mathrm{kg} \mathrm{cm} / \mathrm{cm})$, datanya dapat dilihat dalam tabel 2 .
Tabel 2 : Data hasil uji ketahanan pukul takik $(\mathrm{kg} \mathrm{cm} / \mathrm{cm})$

\begin{tabular}{c|c|c|c|c}
\hline \multirow{2}{*}{ Waktu } & \multicolumn{3}{|c|}{ Ulangan } & \multirow{2}{*}{ Rata-rata } \\
\cline { 2 - 4 } & 1 & 2 & 3 & \\
\hline & & & & \\
13 & 3,3137 & 2,3768 & 2,0587 & 2,5831 \\
17 & 2,4466 & 2,4648 & 2,4557 & 2,4557 \\
19 & 1,2223 & 2,0845 & 2,0924 & 1,7997 \\
21 & 2,1328 & 2,5694 & 2,1494 & 2,2834 \\
& 2,5113 & 2,5113 & 2,4925 & 2,5050 \\
\hline
\end{tabular}

\section{Pembahasan}

Hasil penelitian seperti data pada tabel 1 dan 2 dihitung dengan analisa sidik ragam, baik untuk kekerasan maupun ketahanan pukul takik, hasil perhitungan dapat dilihat dalam tabel 3 dan 4 .

Tabel 3 : Analisa sidik ragam untuk kekerasan

\begin{tabular}{lrrrrrr}
\hline \multicolumn{1}{c}{ Variasi } & db. & JK & RJK. & Fhit. & F 5 \% & F 1 \% \\
\hline Treatment & 4 & 64,30 & 16,075 & 0,352 & 3,11 & 5,04 \\
Error & 10 & 455,67 & 45,567 & & & \\
\hline Total & 14 & 519,97 & & & &
\end{tabular}

Hasil analisa sidik ragam dengan nilai $\mathrm{F}$ hitung $=0,352$ lebih kecil dibanding dengan $\mathrm{F}$ tabel $(5 \%)$ dan (1\%), maka perlakuan dengan variasi waktu proses tidak berpengaruh terhadap kekerasan.

Tabel 4 : Analisa sidik ragam untuk ketahanan pukul takik $(\mathrm{kg} \mathrm{cm} / \mathrm{cm})$

\begin{tabular}{lrrrrrc}
\hline \multicolumn{1}{c}{ Variasi } & db. & JK. & RJK & F hit. & F 5 \% & F 1 \% \\
\hline Treatment & 4 & 1,1812 & 0,2953 & 2,0626 & 3,11 & 5,04 \\
Error & 10 & 1,4742 & 0,1474 & & - & - \\
\hline Total & 14 & 2,6554 & & & &
\end{tabular}

Hasil analisa sidik ragam dengan nilai $\mathrm{F}$ hitung $=2,0626$ lebih kecil dibanding dengan $\mathrm{F}$ tabel $(5 \%$ dan $1 \%$ ), maka perlakuan dengan variasi waktu proses pembuatan kompon polipropilene untuk acuan sepatu tidak berpengaruh terhadap sifat ketahanan pukul takik. 


\section{KESIMPULAN}

Dari hasil penelitian dapat disimpulkan bahwa :

1. Variasi waktu proses pencetakan kompon polipropilene untuk acuan sepatu ternyata tidak berpengaruh pada ketahanan pukul takiknya.

2. Variasi waktu proses pencetakan kompon polipropilene untuk acuan sepatu mempunyai pengaruh pada kekerasan, dimana semakin lama waktu proses kekerasannya semakin turun.

3. Hasil uji kekerasan dan ketahanan pukul takik yang tertinggi dicapai oleh kompon yang diproses dengan waktu 13 menit $(75,53$ shore $D$, dan $2,5831 \mathrm{~kg} \mathrm{~cm} / \mathrm{cm}$ )

\section{PENUTUP}

Dengan selesainya penelitian ini penulis tidak lupa mengucapkan terima kasih kepada Bapak Kepala Balai Besar Penelitian dan Pengembangan Industri Barang Kulit, Karet dan Plastik, dan Bapak Kepala Balai Penelitian Barang Karet dan Plastik Yogyakarta yang telah mempercayakan pelaksanaan penelitian ini sampai selesai, serta Bapak Kepala Pusat Pengendalian Mutu Petrokimia Pertamina Jakarta yang telah membantu pelaksanaan penelitian ini. Dan kepada semua fihak yang telah membantu pelaksantian penelitian ini sampai selesai sesuai dengan rencana.

\section{DAFTAR PUSTAKA}

1. Beck, Ronald D ; Plastic Product Design,2nd, Van Nostrand Reinhold Company, New York.

2. Driver Walter E; Plastic Chemistry and Technology, Van Nostrand Reinhold Company, New York, (1979).

3. Departemen Perindustrian RI., Balai Penelitian dan Pengembangan Industri Medan ; Pengembangan Kaolin di Sumatera - Utara.

4. Gupta, RK. ; Handbook of Small Scale Plastic Industries, Small Business Publication, Roop Nagar, Delhi.

5. Richardson, Terry A. ; Modern Industrial Plastik, Howard W, Sons and Co., Inc., New York.

6. Soentojo, Ir. ; Experiment Design, Universitas Brawijaya, Malang.

7. Suhardjo, Ir. ; Optimasi Proses Injection Moulding, Pusat Pengendalian Mutu Petrokimia, Pertamina, Jakarta, (1988). 